\title{
Quando a família é a principal doença
}

António Santos, ${ }^{*}$ Jerusa Oliveira, ${ }^{*}$ Bertínia Oliveira, ${ }^{*}$ Susana Medeiros**

\section{RESUMO}

Introdução: O caso clínico relata os vários sinais de disfunção familiar detectados pelo médico de família, no decorrer das consultas, bem como alerta para a importância da contextualização holística do doente no âmbito dos Cuidados de Saúde Primários.

Descrição do caso: Trata-se de uma família nuclear, constituída por um casal com uma filha (de 4 anos). P.P., sexo masculino, 27 anos, filho de pais adolescentes, foi abandonado à nascença, sendo acolhido pelos avós maternos, e criado com poucos recursos económicos. Durante a adolescência teve um escasso contacto com a mãe, já casada, com duas filhas e emigrada nos Estados Unidos da América.

Aos 18 anos travou conhecimento com um tio paterno, com quem estabeleceu uma relação de grande afectividade. Este convívio possibilitou uma aproximação ao pai biológico, passando a coabitar ocasionalmente com este, a madrasta e a meia-irmã, 7 anos mais nova, com quem partilhava o quarto. Fruto desta proximidade, desenvolveu-se uma relação incestuosa, descoberta aquando da gravidez da meia-irmã aos 15 anos, na sequência da qual foram expulsos de casa. Desde 2005, ambos os elementos do casal recorreram ao médico de família, em consultas independentes, por queixas inespecíficas sem tradução clínica. A multiplicidade de consultas despertou a suspeita e diagnóstico de disfunção familiar, o que promoveu uma abordagem multidisciplinar, que se revelou significativa para um maior bem-estar familiar.

Comentário: O presente caso pretende chamar a atenção para alguns sinais de alerta de disfunção familiar e para o papel do médico de família na contextualização de sinais e sintomas recorrentes, e na abordagem familiar usando as várias ferramentas de avaliação. Salienta-se de igual modo a importância da colaboração multidisciplinar e integração dos cuidados com vista à melhoria da dinâmica e orientação familiar.

Palavras-chave: Medicina Geral e Familiar; Somatização; Disfunção Familiar; Consanguinidade.

\section{INTRODUÇÃO}

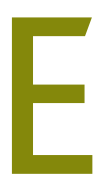

m Medicina Geral e Familiar é impossível dissociar o exercício médico de um conjunto de conhecimentos, aptidões e atitudes dirigidas ao bem-estar da pessoa enquanto indivíduo, interligando-o ao seu contexto familiar e social. A «família» é uma referência na organização da prática médica, podendo ter um papel na etiologia e manutenção dos padrões de saúde, de doença e de comportamento. ${ }^{1}$ A Organização Mundial de Saúde caracterizou a família como «o primeiro agente social envolvido na promoção da saúde e do bem-estar».2

O conceito de «família saudável» é complexo e alvo de estudo de diferentes autores, os quais apresentam diferentes interpretações consoante a sua linha de pen-

*Interno de Medicina Geral e Familiar

*Assistente de Medicina Geral e Familiar

USF AlphaMouro, ACES IX Algueirão - Rio de Mouro samento. No entanto, na actividade do médico de família, há sinais que o podem alertar para problemas que se relacionem com a dinâmica familiar e determinem mal-estar para os seus elementos. Nessas situações é obrigatório aplicar métodos de avaliação familiar, nomeadamente realizar uma entrevista familiar. ${ }^{3-6}$

Assim, o médico de família deverá ser um gestor de cuidados, sendo esta uma das suas competências nucleares. $^{7}$ Deve ainda assumir o papel de gestor de meios/recursos comunitários, de cuidados de saúde (da sua consulta e eventual referenciação) e também, se necessário, de defesa do doente na interface de cuidados. ${ }^{1,7}$

A escolha do presente caso clínico prende-se com o facto de os autores considerarem ser o mesmo exemplificativo de vários aspectos que definem o médico de família e a Medicina Geral e Familiar. Assim, os três aspectos de maior relevo, apresentados ao longo da descrição deste caso são: o reconhecimento de sinais que 
sugeriram problemas familiares detectados pelo médico de família no decorrer das consultas, a preponderância da contextualização holística e visão sistémica do doente no âmbito dos Cuidados de Saúde Primários (CSP) e a necessidade de gerir cuidados. Por outro lado, o mesmo mostra a importância da aplicação de métodos de avaliação familiar para um correcto conhecimento da sua dinâmica e para a identificação de problemas. ${ }^{6}$ Aqui, o médico de família afirma-se como gestor e integrador de cuidados, articulando-se multidisciplinarmente com vista ao bem-estar do indivíduo e da sua família. ${ }^{8}$

\section{DESCRIÇÃO DO CASO}

\section{Identificação}

P.P., sexo masculino de 27 anos, natural e residente no concelho de Sintra, completou o $7^{\circ}$ ano de escolaridade e actualmente é operador manual gráfico. O utente constitui uma família nuclear (fase III do ciclo de vida de Duvall) juntamente com a sua filha de 4 anos e a sua companheira de 20 anos, com quem vive em união de facto.

Os resultados dos instrumentos e escalas de avaliação familiar serão propositadamente apresentados na sequência da descrição do caso para uma melhor compreensão do mesmo.

\section{Contexto clínico}

Aos 15 anos, P.P. inicia acompanhamento clínico esporádico no Centro de Saúde da sua área, contactando com múltiplos médicos de família no espaço de 9 anos. De 2007 a 2009 atravessa um período sem médico de família atribuído, altura em que não há recurso à consulta. Quando é novamente integrado num ficheiro clínico, inicia acompanhamento médico regular.

Em Agosto de 2009, P.P. teve a sua primeira consulta com a sua nova médica de família, após um período de cerca de 2 anos sem médico atribuído.

Recorreu à consulta por queixas de precordialgia, palpitações e cefaleia, negando, até à altura, qualquer problema de saúde de maior relevância.

O exame objectivo não revelou alterações, sendo os sintomas atribuídos a um eventual quadro de ansiedade/somatização.

Durante os meses seguintes, recorreu várias vezes à consulta com múltiplas queixas (sensação de ansiedade, irritabilidade, cefaleias, mialgias, epigastralgias...), mantendo-se o exame objectivo invariavelmente sem alterações.

Em Fevereiro de 2010, a médica de família relacionou os sintomas inespecíficos e aparentemente fruto de somatização, presentes nas várias consultas de P.P., com as idas igualmente frequentes à consulta de L.P., a sua companheira, por motivos muito semelhantes.

É então no final desta consulta que P.P., após ter sido questionado se havia algum problema na sua vida pessoal/profissional, sente que foi estabelecida uma relação de confiança e decide partilhar, pela primeira vez, os seus antecedentes pessoais e familiares com a sua nova médica de família.

\section{Contexto familiar}

P.P. é filho de pais adolescentes, abandonado à nascença, sendo acolhido pelos avós maternos e criado com poucos recursos económicos. Durante a adolescência teve um (escasso) contacto com a mãe, entretanto já casada, com duas filhas e emigrada nos EUA.

Aos 18 anos, travou conhecimento com um tio paterno, toxicodependente e VIH positivo, com quem estabeleceu uma relação de grande afectividade, tendo assistido e sofrido muito com a morte do mesmo. Este convívio levou a uma aproximação ao pai biológico, o qual sempre tentara evitar o contacto com o filho. No entanto, a partir dessa altura, P.P. passou a frequentar ocasionalmente a casa do seu pai onde coabitava também a sua madrasta e a sua meia-irmã (L.P.), 7 anos mais nova, com quem partilhava o quarto. Esta proximidade fomentou o desenvolvimento de uma relação de intimidade, culminando numa relação incestuosa, descoberta aquando da gravidez da sua meia-irmã aos 15 anos. Esta revelação motivou a expulsão de P.P. de casa do seu pai e a deterioração da relação entre eles.

Na sequência desta gravidez foi posto um processo criminal a decorrer em Tribunal contra P.P. por suspeita de violação, apesar de esta ter sido sempre negada pela sua meia-irmã. Embora estivesse grávida, L.P. começou nesta fase a sofrer maus tratos por parte dos seus pais.

Cerca de um mês após o nascimento de C.P., a sua mãe L.P. saiu de casa dos pais e foi viver juntamente com P.P. para casa dos seus avós maternos onde são obrigados a relacionarem-se como irmãos.

A partir desta fase sente que todos 0 «olham de forma diferente» (sic). Este mal-estar por ele sentido con- 
diciona um fraco recurso a amizades e é causa de sofrimento contínuo. Fica igualmente patente, em várias consultas, uma excessiva preocupação com a saúde e bem-estar da sua filha.

Em 2007, P.P. e L.P. conseguiram comprar casa própria onde vivem com a sua filha até à actualidade.

Perante o conhecimento dos antecedentes pessoais de P.P. e do impacto dos mesmos na sua vida, a Médica de Família propôs encaminhamento para a consulta de Psicologia, a qual foi prontamente aceite, iniciando nessa altura terapêutica com Paroxetina $20 \mathrm{mg}$.

\section{Instrumentos e escalas de avaliação familiar aplicados}

Todo o contexto apresentado justificou a necessidade sentida de aplicar algumas ferramentas de avaliação familiar para caracterização da história pessoal e relacional do utente (Figuras 1, 2 e 3).

No que concerne às escalas de avaliação familiar aplicadas, obtiveram-se as seguintes classificações:

- Apgar Familiar de Smilkstein $\rightarrow$ Disfunção acentuada (3)

- Risco Familiar de Garcia-Gonzalez $\rightarrow$ Família em risco médio

- Escala Social de Holmes-Rahe $\rightarrow$ Média vulnerabilidade a doenças causadas pelo stress (190)

- Graffard Familiar $\rightarrow$ Classe social grau III

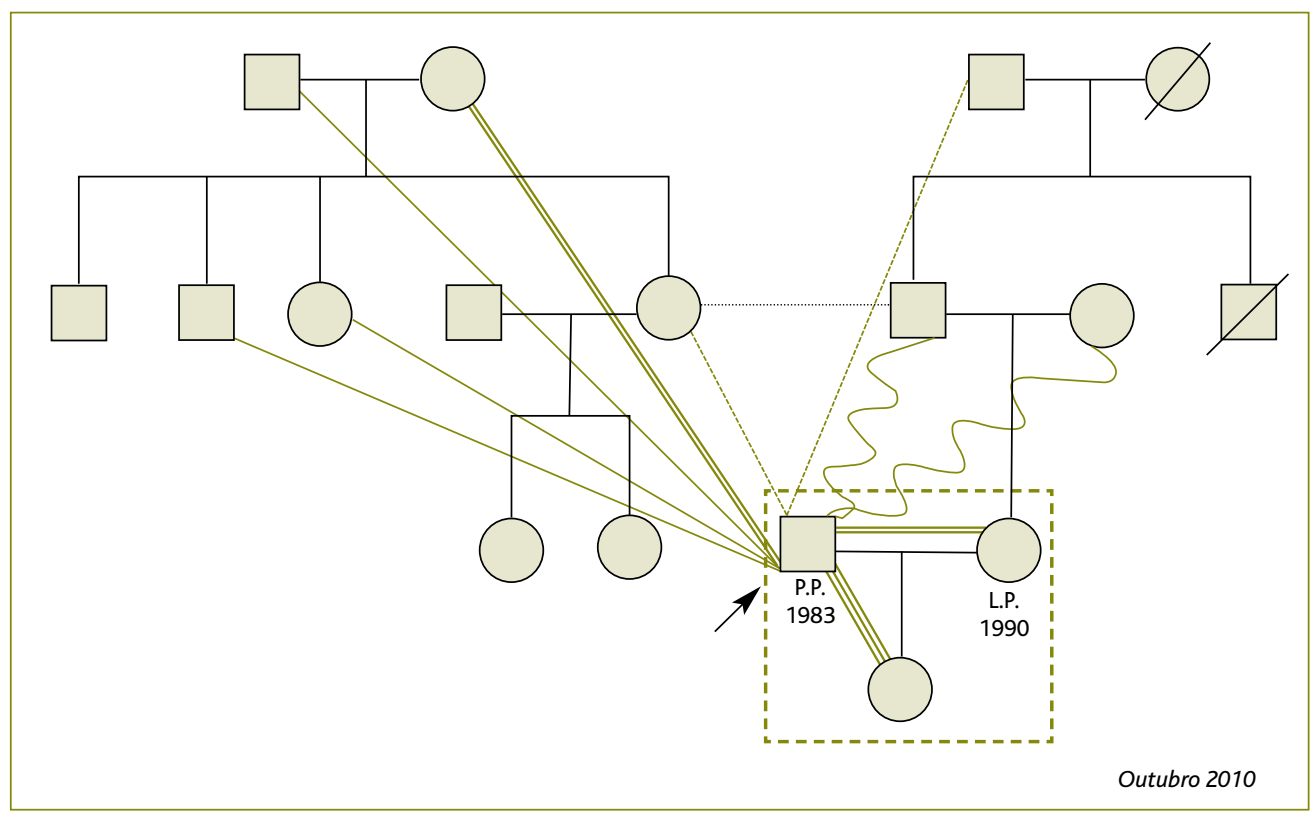

Figura 1. Genograma + Psicofigura de Mitchell.

\section{Problemas identificados}

Na sequência do caso descrito, foram identificados os seguintes problemas:

- Relação incestuosa de P.P. com a sua meia-irmã, que ocorreu na casa do pai de ambos.

- Má relação de P.P. com o pai e a madrasta, que se agravou após a revelação da gravidez de L.P.

- Maior probabilidade de patologia congénita nos filhos do casal com laços de consanguinidade.

- Ambivalência da relação de P.P. com L.P.: meia-irmã/ / esposa e mãe da sua filha.

- Perturbação ansiosa de P.P., fruto dos problemas supracitados.

Perante os dados recolhidos foi criada a hipótese sistémica apresentada no Quadro I.

\section{Plano de actuação}

Atendendo aos problemas identificados, foi necessário criar e estabelecer uma articulação entre a Medicina Familiar e a Psicologia, tendo em linha de conta o sistema marital. Esta articulação visou a definição de papéis de cada um dos elementos deste núcleo familiar. Visou ainda o encaminhamento e aconselhamento genético no contexto de uma eventual futura gravidez.

Assim, numa primeira fase, foi fundamental abordar e trabalhar os sistemas marital e fraternal, de modo a que os elementos da família se reorganizassem perante os problemas.

Em termos práticos, para este objectivo ser atingido aplicou-se o plano de abordagem familiar descrito no Quadro II.

É ainda relevante fornecer aconselhamento parental com o objectivo de proporcionar aos pais informação de carácter prático, não só na transmissão de princípios de aprendizagem, aquisição de conhecimen- 


\begin{abstract}
tos sobre atitudes e comportamentos a adoptar enquanto pais, mas também promovendo competências parentais de comunicação e resolução de problemas.
\end{abstract}

\section{COMENTÁRIO}

De acordo com o Prof. Rui Caeiro, ${ }^{3}$ neste caso clínico estão presentes vários sinais que indiciam um possível diagnóstico de disfunção familiar, tornando a avaliação familiar mandatória: «Sintomas inespecífi-

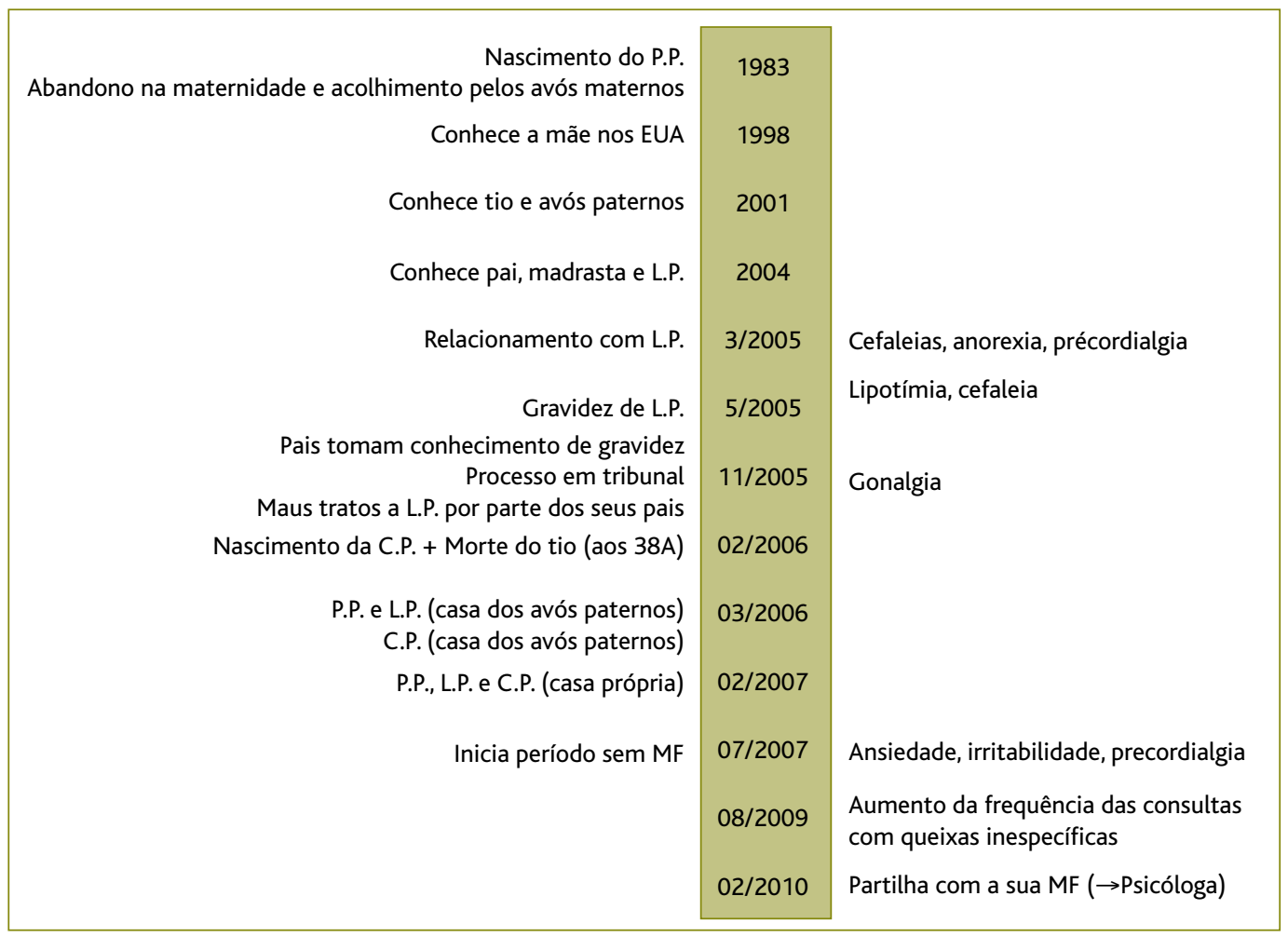

Figura 2. Linha de Vida de Medalie. cos em doentes

com grande frequência de consultas sem doença orgânica»; «Utilização excessiva dos serviços de saúde ou consultas frequentes a diferentes membros da família»; «Problemas emocionais ou de comportamento» $\mathrm{e}$ «Sempre que o modelo biomédico tradicional se apresente inadequado ou insuficiente».

Quando se consultaram os processos de P.P. e da sua companheira, constatou-se que, desde 2005, ambos os elementos do casal recorreram ao médico de família, em consultas independentes, por queixas inespecíficas sem tradução clínica. Coincide esta data com o ano em que iniciaram o seu relacionamento, o qual optaram por não partilhar com o médico assistente, provavelmente por ausência de um seguimento clínico longitudinal.

No caso clínico apresentado, apenas na quarta consulta com a sua médica de família é que P.P. decidiu partilhar, uma vez criadas as condições apropriadas, os seus antecedentes pessoais e familiares. Estes muito provavelmente estão relacionados com várias das queixas apresentadas nas consultas prévias. O conhecimento dos seus antecedentes pessoais possibilitou um melhor

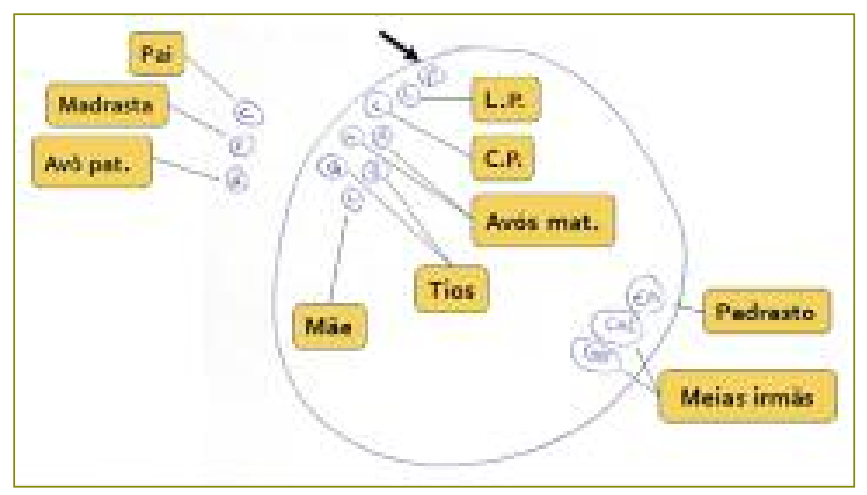

Figura 3. Círculo Familiar de Thrower.

enquadramento da situação clínica apresentada e promoveu uma abordagem multidisciplinar, que se revelou significativa para um maior bem-estar familiar.

O facto de P.P. ter contactado com múltiplos médicos assistentes numa fase preponderante da sua vida dificultou um acompanhamento continuado e global das questões familiares, que neste caso assumem um papel de destaque. No entanto, pode-se perceber a im- 


\section{QUADRO I. Hipótese Sistémica.}

Que as queixas somáticas e ansiedade apresentadas por P.P. sejam a tradução da sua ambiguidade perante os papéis de companheiro/irmão de L.P., resultante por um lado da sua história pessoal de afastamento do pai biológico e da irmã L.P. e por outro lado da situação de proximidade física e afectiva que iniciou com L.P. quando começou a conviver com o pai.

P.P. cresceu afastado da meia-irmã L.P.

$\downarrow$

Relação de coabitação/relação amorosa entre P.P. e L.P. $\downarrow$

Gravidez de L.P./paternidade de P.P.

$\downarrow$

Ambiguidade de papéis/reprovação familiar e social

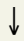

Ambivalência/ansiedade em P.P.

\section{QUADRO II. Plano de Abordagem Familiar. \\ Convidar para consulta P.P. e L.P. \\ $\downarrow$ \\ Observar a sua interacção; Questionar \\ $\downarrow$ \\ Identificação dos problemas por cada elemento \\ $\downarrow$}

Abordagem em comum dos problemas; Escuta reflexiva

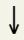

Identificação de soluções possíveis, adequadas e aceites por ambos

$\downarrow$

Elaboração de planos para pôr em prática as soluções encontradas

$\downarrow$

Acompanhamento da execução dos planos; fornecimento de apoio emocional

portância que algumas ferramentas de avaliação familiar podem ter. Em contextos específicos e aplicadas atempadamente, como neste caso, podem clarificar muito precocemente situações ocultadas por queixas recorrentes e inespecíficas.

Os antecedentes de P.P. condicionam a sua relação com o seu meio social e profissional. Existe uma ambivalência entre "culpa» e «sensação de dever cumprido». Esta ambivalência vai mais além quando nos apercebemos que assume face ao pai, ao Tribunal e à própria sociedade a sua relação marital com L.P., mas que, por outro lado, vê negada pelos mesmos a possibilidade de reconhecimento do casal que forma com L.P.

É facilmente entendido por esta descrição que esta vivência vá condicionando as múltiplas relações que estabelece na sua vida e simultaneamente seja um factor de stress contínuo interferindo com o seu todo. Naturalmente, tem implicações com a forma como se relaciona com os outros e com o seu próprio eu. Do ponto de vista clínico, o seu mal-estar, inerente a todo o contexto já descrito, condicionou uma série de episódios de somatização de difícil abordagem (quando olhados fora do seu contexto), a presença de outro elemento da família em várias consultas independentes da sua e ainda uma preocupação excessiva quando a filha era observada em consulta de vigilância de saúde. Apesar de não ter existido, de modo completamente expresso, um pedido de ajuda indicativo da direcção que este casal pretendia dar à sua relação, indirectamente, e tomando em linha de conta as atitudes expressas, quer por P.P., quer por L.P., pode-se assumir que procuravam ser vistos num sistema marital.

O entendimento por parte do médico de família deste contexto foi fundamental para o enquadramento clínico, possibilitando a realização de um correcto plano, que fosse realmente ao encontro do principal problema que trazia P.P. e a esposa à consulta.

Permitiu ainda uma maior definição de papéis e uma melhor orientação desta situação, com o objetivo de minorar o sofrimento desta família. A identificação do problema e o estabelecimento de um plano foram cruciais para a orientação de P.P. e L.P.

Este plano incluiu a intervenção psicológica e o trabalho de clarificação de papéis. ${ }^{9-10}$ Atendendo a que a psicóloga que assumiu o seguimento do P.P. tinha formação em Terapia Familiar, houve, por parte da mesma, uma abordagem nesse sentido. Realizou várias consultas com o casal, tentando perceber e orientar o que 
ambos pretendiam da sua relação. Após o início deste trabalho com a psicóloga, o número de consultas com a sua médica de família reduziu e, quando as mesmas surgiram, foi em contexto de situação aguda de causa orgânica ou em contexto de vigilância de saúde. Notouse ainda uma postura mais tranquila e tornou-se mais frequente a vinda em conjunto do casal à consulta.

O médico de família encontra-se, portanto, numa posição privilegiada para realizar uma abordagem holística aos seus pacientes. A prestação de cuidados longitudinais permite-lhe criar com estes uma relação que facilita o conhecimento do seu contexto biopsicossocial e assim uma mais correcta planificação e gestão dos seus problemas.

\section{AGRADECIMENTOS}

Agradecimento à Dr ${ }^{\mathrm{a}}$ Cássia Monteiro, Psicóloga do ACES IX Algueirão Rio de Mouro.

\section{REFERÊNCIAS BIBLIOGRÁFICAS}

1. Sampaio D, Resina T. Família: Saúde e Doença. Lisboa: Instituto de Clínica Geral da Zona Sul; 1994.

2. World Health Organization. Statistical Indices of Family Health. Geneva:WHO; 1991. p. 589-617.
3. Caeiro RT. Registos Clinicos em Medicina Familiar. Lisboa: Instituto de Clínica Geral da Zona Sul; 1991.

4. Barker P. Fundamentos da Terapia Familiar. Lisboa: Climepsi; 2000.

5. Laginha T. Terapia familiar em Medicina Geral e Familiar. Rev Port Clin Geral. 2007 Mai-Jun; 23 (3): 331-6.

6. Rebelo L. Família e cuidados de saúde. Rev Port Clin Geral 2007 MaiJun; 23 (3): 295-7.

7. Allen J, Gay B, Crebolder H, Heyrman J, Svab Igor, Ram P. A Definição Europeia de Medicina Geral e Familiar (Clínica Geral/Medicina Familiar): versão reduzida - EURACT, 2005. Rev Port Clin Geral 2005 SetOut; 21 (5): 511-6.

8. Ribeiro C. Família, saúde e doença: o que diz a investigação. Rev Port Clin Geral 2007 Mai-Jun; 23 (3): 299-306.

9. Ausloos G. A Competência das Famílias. $2^{\text {a }}$ ed. Lisboa: Climepsi; 2003.

10. Costa JM. A terapia como diálogo. Mosaico 2011; 47: 12-3.

\section{CONFLITOS DE INTERESSE}

Os autores declaram não possuir interesses financeiros, ligações pessoais ou outros conflitos de interesse.

\author{
ENDEREÇO PARA CORRESPONDÊNCIA \\ Jerusa Oliveira \\ Rua Cidade de Lagos, lote 64, 1685-670 Famões, Odivelas \\ E-mail: jerusa.r.g.oliveira@gmail.com
}

Recebido em 04/06/2012

Aceite para publicação em 26/02/2013

\section{ABSTRACT}

\section{WHEN THE FAMILY IS THE MAIN DISEASE}

Introduction: This case study describes multiple signs of family dysfunction detected by a general practitioner (GP) during office visits as well as attention to the context of the patient in primary health care.

Case description: The case involves a nuclear family composed of a couple and their 4 year-old daughter. The index patient is a 27 year-old male who was abandoned at birth by his teenage parents. He was raised by his maternal grandparents, who had few economic resources. During his adolescence he had minimal contact with his mother, who was already married with two daughters and living abroad. At the age of 18 he met a paternal uncle, with whom he established a strong relationship. This interaction led to a reunion with his biological father. The patient occasionally lived with him, his stepmother, and his half-sister, seven years younger, with whom he shared a room. They developed an incestuous relationship, which was revealed as a result of the pregnancy of his half-sister who was 15 at the time. They were then evicted from their father's home. Both members of the couple subsequently visited the same GP in independent consultations with nonspecific complaints without a clinical explanation. The multiple consultations aroused suspicion of family dysfunction. A multidisciplinary approach was helpful in promoting family welfare.

Comment: This case study draws attention to warning signs of family dysfunction, the role of the GP in assessing recurrent signs and symptoms, and the use of family assessment tools. The importance of multidisciplinary collaboration for integration of care and family counseling to improve family dynamics are noted.

Keywords: Family Practice; Somatoform Disorders; Family Conflict; Consanguinity. 